\title{
Theoretical Study on Regioselectivity of the Diels-Alder Reaction between 1,8-Dichloroanthracene and Acrolein
}

\author{
Mujeeb A. Sultan ${ }^{1, *}$, Usama Karama ${ }^{1}$, Abdulrahman I. Almansour ${ }^{1}$ and Saied M. Soliman ${ }^{2,3, *}$ \\ 1 Chemistry Department, College of Science, King Saud University, P.O. Box 2455, Riyadh 11451, Saudi Arabia; \\ Karama@ksu.edu.sa (U.K.); almansor@ksu.edu.sa (A.I.A.) \\ 2 Department of Chemistry, Rabigh College of Science and Art, P.O. Box 344, Rabigh 21911, Saudi Arabia \\ 3 Department of Chemistry, Faculty of Science, Alexandria University, P.O. Box 426, Ibrahimia, \\ Alexandria 21321, Egypt \\ * Correspondence: alhosami1983@yahoo.co.uk (M.A.S.); saied1soliman@yahoo.com (S.M.S.); \\ Tel.: +96-6593-636-123 (M.A.S.); +96-6565-450-752 (S.M.S.)
}

Academic Editors: Alessandro Ponti and Derek J. McPhee

Received: 21 August 2016; Accepted: 17 September 2016; Published: 23 September 2016

\begin{abstract}
A theoretical study of the regioselectivity of the Diels-Alder reaction between 1,8-dichloroanthracene and acrolein is performed using DFT at the B3LYP/6-31G $(\mathrm{d}, \mathrm{p})$ level of theory. The FMO analysis, global and local reactivity indices confirmed the reported experimental results. Potential energy surface analysis showed that the cycloadditions (CAs) favor the formation of the anti product. These results are in good agreement with the reported results obtained experimentally where the anti is the major product.
\end{abstract}

Keywords: Diels-Alder cycloaddition; regioselectivity; DFT; transition state

\section{Introduction}

The Diels-Alder cycloaddition is one of the most useful reactions in organic synthesis, and it is among the most atomically economical and reliable carbon-carbon bond forming methods known in organic chemistry [1]. The Diels-Alder reactions of nonsymmetrical dienes with unsymmetrical dienophiles have considerable interest to synthetic chemists due to their stereoselectivity and regioselectivity [2-4]. The ability to predict the regioselectivity and stereoselectivity of Diels-Alder reactions is a cornerstone of their use in synthesis. The theoretical chemistry is a useful approach for predicting conformations and properties of the molecules [5]. Meek et al. mentioned that Diels-Alder reactions of many polynuclear aromatic compounds with maleic anhydride, or similar dienophiles, should be undertaken from a theoretical point of view [6]. The Diels-Alder reactions of anthracene with maleic anhydride, and its benzo derivatives, have been reported and analyzed using SCF-MO theory [7], Two isomers of 5,12-dihydro-5,12-ethanonaphthacene-13-carbaldehyde, as a result of the reaction between naphthacene and acrolein, were experimentally obtained and validated by conformational research at the B3LYP /6-31G* level [8]. In this manuscript, the accuracy of theoretical calculations is used to understand the regioselectivity of the Diels-Alder reaction between the diene (1,8-dichloroanthracene) and dienophile (acrolein), which produced experimentally, in the course of the total synthesis of antidepressants, the two isomers syn (10\%) and anti (66\%). The two isomers was separated and distinguished by ${ }^{1} \mathrm{H}-\mathrm{NMR}[9,10]$.

\section{Computational Details}

The geometry optimizations of the reactants, transition states (TSs) and cycloaddition products (CAs) were carried out using the DFT/B3LYP [11,12] functional and 6-311G(d,p) as a basis set. Gaussian 03 was used to perform all calculations [13]. The frequency calculations were carried out to 
characterize stationary points to ensure that minima and transition states have zero and one imaginary frequency, respectively [14]. One negative vibrational mode corresponding to the motion during the formation of the new $\mathrm{C}-\mathrm{C}$ bonds was obtained from each transition state. The Gaussview software was used to assign vibrational mode through visual inspection and animation [15]. The recorded total energies involving zero point energy (ZPE) corrections are obtained at $298.15 \mathrm{~K}$. The global electrophilicity index $(\omega)$ [16-19] was calculated by the equation:

$$
\omega=\left(\mu^{2} / 2 \eta\right)
$$

where $\mu$ is the electronic chemical potential, $\mu=\left(E_{H}+E_{L}\right) / 2$, and $\eta$ is the chemical hardness, $\eta=\left(E_{L}-E_{H}\right)$.

The nucleophilicity index, $\mathrm{N}$ [7] is defined using the equation

$$
\mathrm{N}=\mathrm{E}_{\mathrm{H}(\mathrm{Nu})}-\mathrm{E}_{\mathrm{H}(\mathrm{TCE})}
$$

Tetracyanoethylene (TCE) is selected as reference [20,21].

The natural population analysis (NPA) was used to compute DFT-based local reactivity and atomic electronic population indices [22]. The local electrophilicity indices $\omega^{+}$and $\omega^{-}$of atom $\mathrm{k}$ are determined with the help of Fukui index $f$ using these following equations:

$$
\begin{aligned}
& \omega^{+}=\omega f_{k}^{+}=\omega\left[Q_{k}(N+1)-Q_{k}(N)\right] \text { For nucleophilic attack, } \\
& \omega^{-}=\omega f_{k}^{-}=\omega\left[Q_{k}(N)-Q_{k}(N-1)\right] \text { For electrophilic attack, }
\end{aligned}
$$

where $Q_{k}(N), Q_{k}(N+1)$, and $Q_{k}(N-1)$ represent electronic population of site $k$ in neutral, anionic, and cationic systems, respectively [23].

\section{Results and Discussion}

Referring to the Scheme 1, acrolein and 1,8-dichloroanthracene 2 reacted at room temperature with the help of a catalytic amount of boron trifluorideetherate, through a Diels-Alder [4 +2] cycloaddition reaction, and afforded the two separable isomers syn as minor (10\%) and anti as major (66\%) [10]. The obtained isomers is due to the fact that both the 1,8-dichloroanthracene (diene) and acrolein (dienophile) were unsymmetrical. The assignment of the syn and anti isomers by ${ }^{1} \mathrm{H}-\mathrm{NMR}$ analysis was not troublesome, the bridge-head protons $\mathrm{H}-(\mathrm{C}-4)$ and $\mathrm{H}-(\mathrm{C}-1)$ of the syn-isomer has a triplet signal appearing at $\delta 4.42 \mathrm{ppm}$ and a doublet signal at $\delta 4.71 \mathrm{ppm}$, respectively. However, the bridge-head protons $\mathrm{H}-(\mathrm{C}-1)$ and $\mathrm{H}-(\mathrm{C}-4)$ of the anti-isomer have triplet signals appearing at $5.48 \mathrm{ppm}$ and doublet signal at $4.75 \mathrm{ppm}$, respectively. The downfield shifting of the H-(C-1) in the syn-isomer and H-(C-1) in the anti-isomer is a result of a deshielding effect of the chlorine atoms.

A theoretical investigation of the regioselectivity of the CA reaction between 1,8-dichloroanthracene (diene) and acrolein (dienophile) was performed (Scheme 1). Table 1 showed the FMO energies $(\mathrm{eV})$, chemical potential $(\mu)$, electrophilicity $(\omega)$ and the global electrophilicity $(\mathrm{eV})$ of the reactants. Figure 1 presents the possible interactions between the $\mathrm{FMOs}\left(\mathrm{HOMO}\right.$ diene $\left.-\mathrm{LUMO}_{\text {dienophile }}\right)$ and $\left(\mathrm{HOMO}_{\text {dienophile }}-\mathrm{LUMO}_{\text {diene }}\right)$. Table 1 and Figure 1 exhibited that the gap $\mathrm{HOMO}_{\text {acrolein }}-$ $\mathrm{LUMO}_{1,8 \text {-dichloroanthracene }}(4.84 \mathrm{eV})$ is larger than the $\mathrm{HOMO}_{1,8 \text {-dichloroanthracene }}-\mathrm{LUMO}_{\text {acrolein }}(3.84 \mathrm{eV})$ one. Therefore, the major interaction occurs between the HOMO of 1,8-dichloroanthracene and the LUMO of acrolein. Thus, this cycloaddition is a normal electronic demand (NED) reaction. The chemical potential of acrolein $(-4.6053 \mathrm{eV})$ is less than that of 1,8-dichloroanthracene $(-4.1096 \mathrm{eV})$, indicating that charge movement will occur from 1,8-dichloroanthracene to electron poor alkene (acrolein). This result agrees well with the FMO analysis. 
<smiles>Clc1cccc2cccc(Cl)c12</smiles>

1,8-dichloroanthracene<smiles></smiles>

acrolein

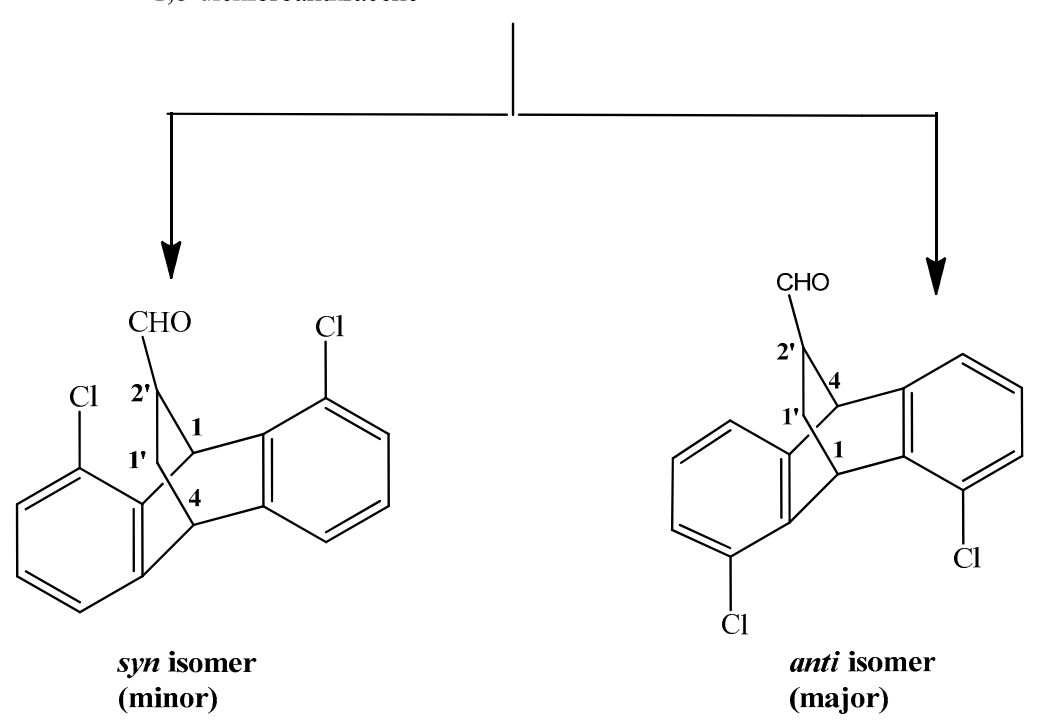

Scheme 1. The syn and anti products of the Diels-Alder reaction between 1,8-dichloroanthracene and acrolein.

According to the classification proposed by Domingo et al. (electrophiles: $\omega>1.50 \mathrm{eV}$-strong, $1.50>\omega>0.80 \mathrm{eV}$-moderate, $\omega<0.80 \mathrm{eV}$-marginal; nucleophiles: $\mathrm{N}>3.00 \mathrm{eV}$-strong, $3.00>\mathrm{N}>2.00 \mathrm{eV}$-moderate, $\mathrm{N}<2.00 \mathrm{eV}$-marginal) [13-15], the 1,8-dichloroanthracene molecule could be considered as a strong nucleophile and electrophile, whereas acrolein is a moderate nucleophile and strong electrophile. Based on the values of the nucleohilicity index $(\mathrm{N})$ listed in Table 1, the diene, 1,8-dichloroanthracene has higher nucleophilicity $(3.5231 \mathrm{eV})$ than the dienophile, and acrolein, $(2.1595 \mathrm{eV})$. In agreement with the NED character CA reaction, the 1,8-dichloroanthracene acts as a nucleophile while acrolein is the electrophile. Unfortunately, it is found that the global electrophilicity of acrolein $(2.0363 \mathrm{eV})$ is lower than that of the diene $(2.4322 \mathrm{eV})$. Based on these results, the alkene will act as a nucleophile, while 1,8-dichloroanthracene will act as an electrophile. As a result, one could expect that the reaction of 1,8-dichloroanthracene with dienophile possesses an inverse electronic demand (IED) character. The global electrophilicity results are in contradiction with FMO and chemical potential data. The low polar character of this CA reaction, as indicated by the small electrophilicity difference between the diene and dienophile $(\Delta \omega=0.40 \mathrm{eV})$, could explain such a contradiction [24-27]. In this regard, the amount of charge transfer (CT) that occurred at the transition state was analyzed, and the results are given in Table 2. The low amount of CT that occurred at the transition states confirmed not only the low polar character of this CA reaction, but also its NED nature.

Table 1. The $\mathrm{E}_{\mathrm{HOMO}}, \mathrm{E}_{\mathrm{LUMO}}$, chemical potential $(\mu)$, electrophilicity $(\omega)$ and global nucleophilicity indices for the reactants in $(\mathrm{eV})$.

\begin{tabular}{cccccc}
\hline Reactant & $\mathbf{E}_{\text {HOMO }}$ & $\mathbf{E}_{\text {LUMO }}$ & $\boldsymbol{\mu}$ & $\boldsymbol{\omega}$ & $\mathbf{N}$ \\
\hline 1,8-dichloroanthracene & -5.8456 & -2.3737 & -4.1096 & 2.4322 & 3.5231 \\
acrolein & -7.2092 & -2.0014 & -4.6053 & 2.0363 & 2.1595 \\
\hline
\end{tabular}




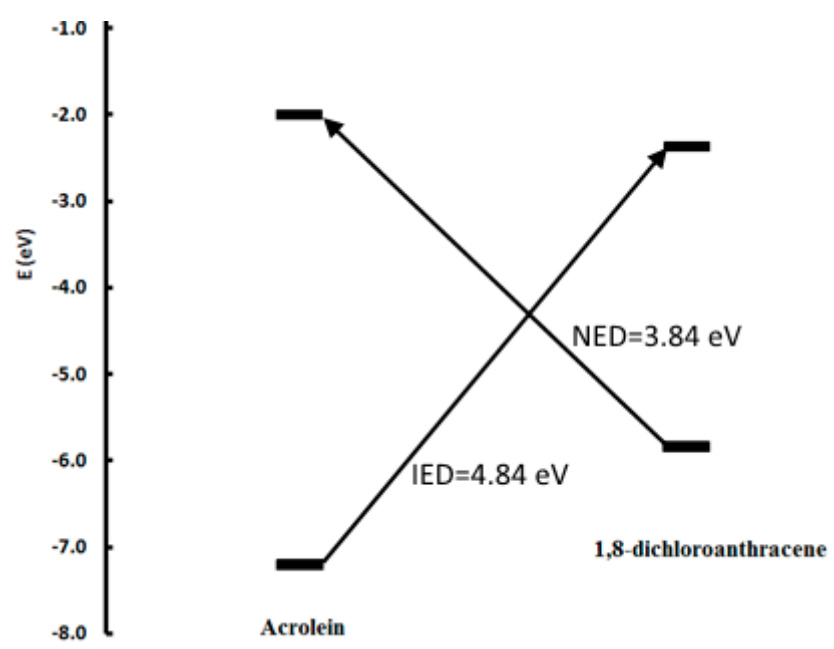

Figure 1. The possible interactions between the FMOs of 1,8-dichloroanthracene and acrolein.

Table 2. The amount of charge transfer (CT) from diene to dienophile.

\begin{tabular}{cc}
\hline Transition State (TS) & Charge Transfer (e) \\
\hline TS-1 & 0.0337 \\
TS-2 & 0.0333 \\
TS-3 & 0.0448 \\
TS- 4 & 0.0407 \\
\hline
\end{tabular}

According to the Houk rule [28], the large-large and small-small interactions are more favored than the large-small one. The FMO coefficients values of acrolein and 1,8-dichloroanthracene are given in Table S1 (Supplementary data). It is clear that the large-large interaction between C1 of diene and $\mathrm{C}^{\prime}$ of acrolein as well as the small-small interaction between $\mathrm{C} 4$ of diene and $\mathrm{C} 2{ }^{\prime}$ of acrolein are the most favored. Hence, the formation of the anti regioisomer as a major product is the most favored. Accordingly, Houk's rule FMO model correctly reproduces the reported experimental regioselectivity of this CA reaction. For more visualization of these interactions, Scheme 2 showed the coefficients with atom numbering.

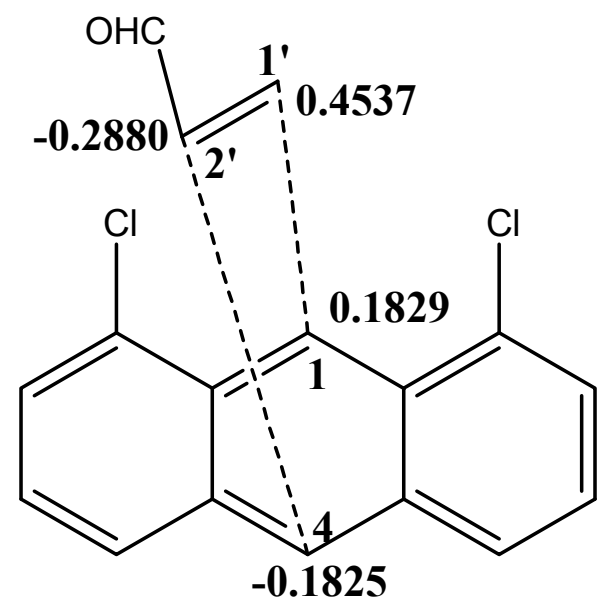

Scheme 2. The FMO coefficients of 1,8-dichloroanthracene (HOMO) and acrolein (LUMO).

The local electrophilicity indices $\omega^{+}$and $\omega^{-}$of atom $\mathrm{k}$ were calculated to clarify the regioselectivity of the studied CA reaction. The values of the Fukui indices $f_{k}$ and local electrophilicity 
indices $\omega_{k}$ were recorded in Table S2 (Supplementary data). We have sketched these interactions in Scheme 3 in order to better visualize them. In the reaction of 1,8-dichloroanthracene and acrolein, the most favorable two-center interaction takes place between $\mathrm{C} 1$ and $\mathrm{C} 4$ of the diene nucleophile with $\mathrm{C}^{\prime}$ and $\mathrm{C} 2^{\prime}$ of the alkene electrophile, respectively. These results are in good agreement with the results obtained experimentally where the anti is the major product.

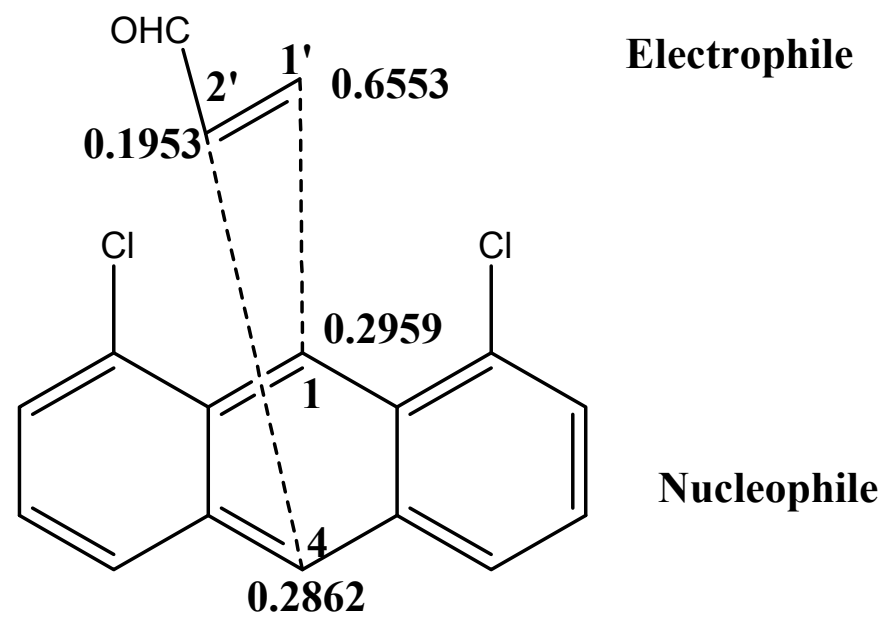

Scheme 3. The favorable interactions based on local electrophilicity indices $\left(\omega^{+}\right.$of diene nucleophile, $\omega^{-}$of alkene electrophile).

\section{Molecular Mechanism}

The possible pathways for the studied CA reaction are shown in Scheme 4 . The cycloaddition reaction of 1,8-dichloroanthracene with acrolein could occur through four pathways. In this scheme, the two suggested ant $i$ isomers differ in the conformation of the $O$ atom of the aldehyde group (pathways 1 and 2). In anti-1, the $O$-atom is in the side of the benzene ring, while, in case of anti-2, the $O$ atom of the aldehyde group is pointed outside the benzene ring. The same is the difference between the two syn isomers (syn-1 and syn-2). The calculated structures of the four TSs are given in Figure 2. In addition, the newly forming $\mathrm{C}-\mathrm{C}$ bond lengths at the transition state structure are shown in the same figure. Moreover, the energies (a.u.) and relative energies (kcal/mol) of the TSs were reported in Table S3 (Supplementary data). The potential energy surfaces (PESs) for all reaction pathways are shown in Figure 3.

The product syn-1 is the most favored thermodynamically as indicated by the theoretically calculated energy difference between the reactants and product. In contrast, the calculated activation energies of the different reaction pathways between 1,8-dichloroanthracene and acrolein exhibited that the pathway 1 (anti-1) is the most favored kinetically compared to the other pathways. The energy difference between the anti-1 and syn-1 isomers is low $(0.301 \mathrm{kcal} / \mathrm{mol})$. In addition, the small activation energy difference between pathways 1 and 2 is small. These results agree well with the formation of a mixture of the two regioisomers observed experimentally. In addition, the anti-1 and syn-1 products are more stable both thermodynamically and kinetically than the anti-2 and syn-2 isomers, respectively. The energy difference between the syn-1 and syn-2 conformers $(3.2974 \mathrm{kcal} / \mathrm{mol})$, as well as anti-1 and anti-2 conformers $(1.876 \mathrm{kcal} / \mathrm{mol})$, suggested the possible interconversion among each conformer pair. The interconversion between the anti products is energetically more favored than that for the syn ones. It is worth noting that the catalyst plays an important role for lowering the activation energy of the chemical reactions, which already could occur with higher experimental efforts if the catalyst does not exist, but it will not affect the regioselectivity of the studied reaction. Regardless of the role of the catalyst, which makes the reaction go faster than its absence, this modeling study succeeded in explaining why the anti isomer is the major product, while the syn is the minor one. 

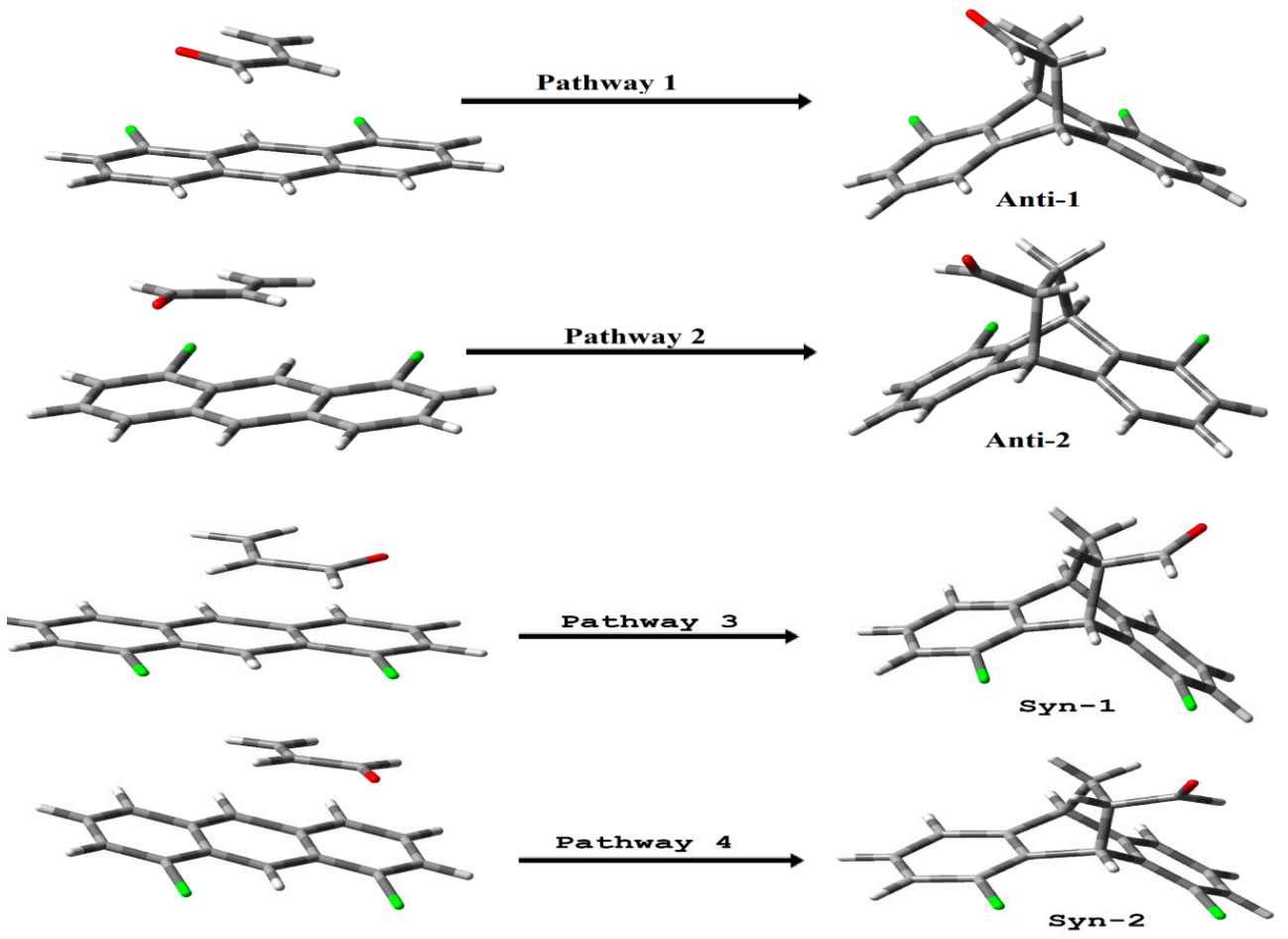

Scheme 4. The four pathways of the CA reaction between 1,8-dichloroanthracene and acrolein.

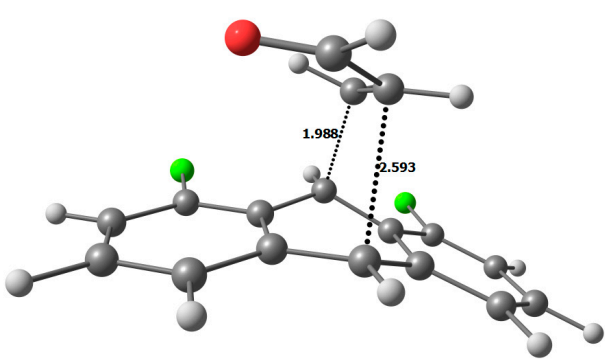

Pathway 1 (TS-1)

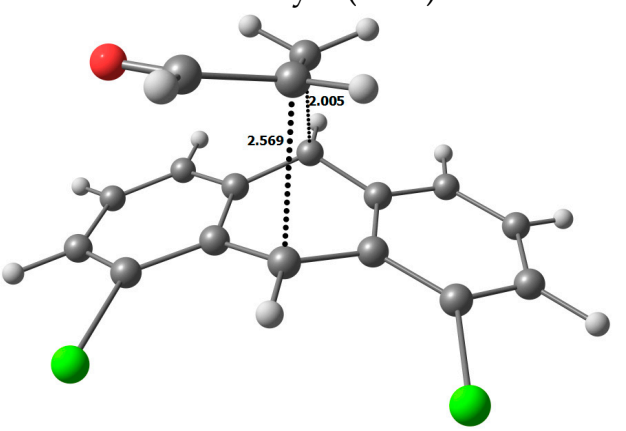

Pathway 3 (TS-3)

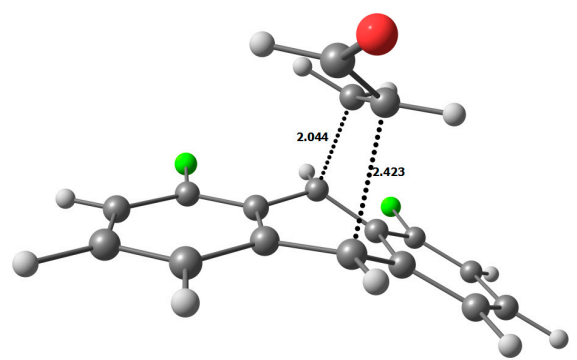

Pathway 2 (TS-2)

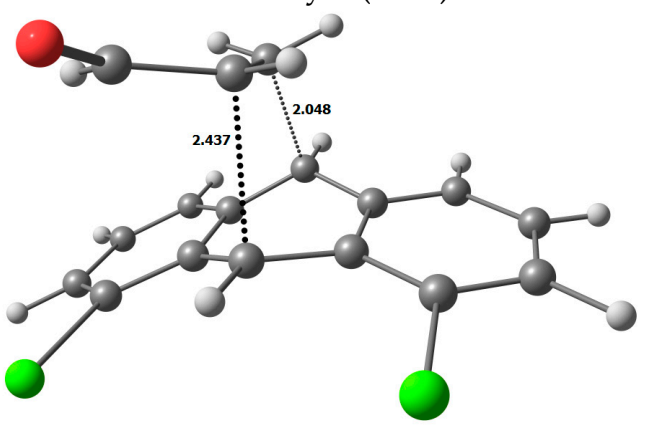

Pathway 4 (TS-4)

Figure 2. The four transition state structures for the CA reaction between 1,8-dichloroanthracene and acrolein. 


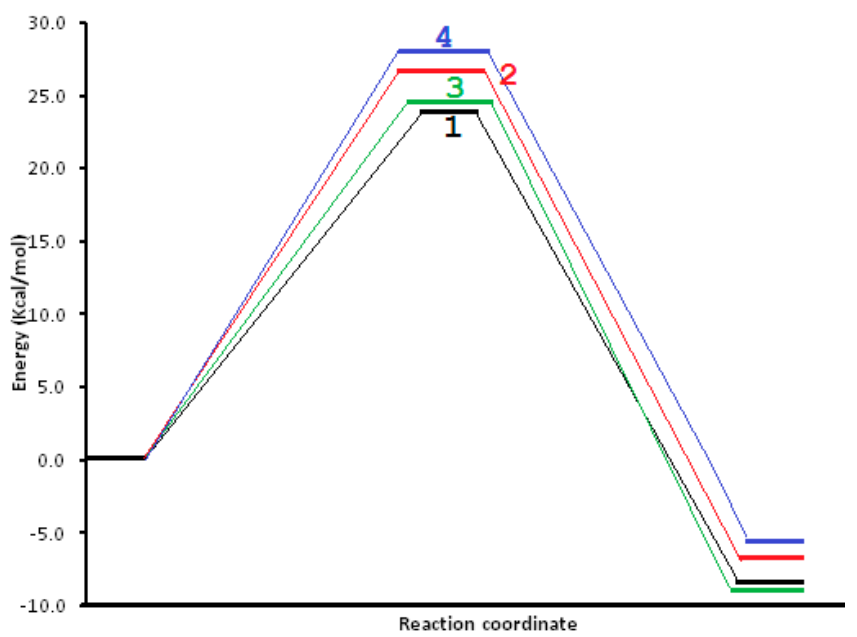

Figure 3. Energy profiles, in $\mathrm{kcal} / \mathrm{mol}$ for the four pathways of the CA reactions between 1,8-dichloroanthracene and acrolein.

\section{Conclusions}

The FMO analyses indicated a normal electron demand reaction. The global and local reactivity indices confirmed the regioselective formation of the anti isomer. The reaction has low polar character with little charge transfer predicted at the transition state. The anti product has the least activation energy; hence, the reaction gave, selectively, the anti product as the major and the syn as the minor product. These results are in good agreement with the reported results obtained experimentally.

Supplementary Materials: Supplementary materials can be accessed at: http:/ /www.mdpi.com/1420-3049/21/ $10 / 1277 /$ s1.

Acknowledgments: The authors extend their appreciation to the Deanship of Scientific Research at King Saud University, for funding the work through the research group project No. RGP-128.

Author Contributions: M.A.S., U.K. and A.I.A. contributed the design, synthesis and characterization of the products. S.M.S. performed the theoretical investigations. M.A.S., U.K. and S.M.S. wrote the manuscript.

Conflicts of Interest: The authors declare no conflict of interest.

\section{References}

1. Brocksom, T.J.; Nakamura, J.; Ferreira, M.L.; Brocksom, U. The Diels-Alder reaction: An update. J. Braz. Chem. Soc. 2001, 12, 597-622. [CrossRef]

2. Mehta, G.; Uma, R. Stereoelectronic control in Diels-Alder reaction of dissymmetric 1,3-dienes. Acc. Chem. Res. 2000, 33, 278-286. [CrossRef] [PubMed]

3. Kanishchev, O.S.; Sanselme, M.; Bouillon, J.-P. Hetero-Diels-Alder reactions of perfluoroalkyl thioamides with electron-rich 1,3-dienes: Synthesis of new 2-aminosubstituted-3, 6-dihydro-2h-thiopyrans and related compounds. Tetrahedron 2013, 69, 1322-1336. [CrossRef]

4. Khan, R.; Singh, T.P.; Singh, M.D. Letter highly regioselective Diels-Alder reaction of 9-substituted anthracenes with citraconic anhydride. Synlett 2014, 25, 696-700.

5. Huang, D.; Tan, Y.; Sun, Y.; Zheng, C.; Wang, Z. Quantum chemical calculation study on terphenyl arylamines hole transport materials. J. Soc. Inf. Display 2015, 23, 182-185. [CrossRef]

6. Meek, J.S.; Dewey, F.M.; Hanna, M.W. Diels-Alder reactions of naphthacene. J. Org. Chem. 1967, 32, 69-72. [CrossRef]

7. Dewar, M.J.; Pyron, R.S. Nature of the transition state in some diels-alder reactions. J. Am. Chem. Soc. 1970, 92, 3098-3103. [CrossRef]

8. Karama, U.; El-Azhary, A.A.; Almansour, A.I.; Al-Kahtani, A.A.; Al-Turki, T.M.; Jaafar, M.H. Computational and spectral investigation of 5,12-dihydro-5,12-ethanonaphthacene-13-carbaldehyde. Molecules 2011, 16, 6741-6746. [CrossRef] [PubMed] 
9. Karama, U.S.; Sultan, M.A.S.; Tahir, K.E.H.E.; Almansour, A.I. Antidepressant Compounds. Patent US9125866 B1, 8 September 2015.

10. Karama, U.; Sultan, M.A.; Almansour, A.I.; El-Taher, K.E. Synthesis of chlorinated tetracyclic compounds and testing for their potential antidepressant effect in mice. Molecules 2016, 21, 61. [CrossRef] [PubMed]

11. Becke, A.D. Density-functional exchange-energy approximation with correct asymptotic behavior. Phys. Rev. A 1988, 38, 3098. [CrossRef]

12. Lee, C.; Yang, W.; Parr, R.G. Development of the colle-salvetti correlation-energy formula into a functional of the electron density. Phys. Rev. B 1988, 37, 785. [CrossRef]

13. Frisch, M.; Trucks, G.; Schlegel, H.; Scuseria, G.; Robb, M.; Cheeseman, J.; Montgomery, J., Jr.; Vreven, T.; Kudin, K.; Burant, J.; et al. Gaussian 03, Revision c. 02; Gaussian Inc.: Wallingford, CT, USA, 2004.

14. Nacereddine, A.K.; Yahia, W.; Bouacha, S.; Djerourou, A. A theoretical investigation of the regioand stereo-selectivities of the 1,3-dipolar cycloaddition of $C$-diethoxyphosphoryl- $N$-methylnitrone with substituted alkenes. Tetrahedron Lett. 2010, 51, 2617-2621. [CrossRef]

15. Dennington, R.; Keith, T.; Millam, J. GaussView, Version 5. Semichem Inc.: Shawnee Mission, KS, USA, 2009.

16. Parr, R.G.; Szentpaly, L.; Liu, S. Electrophilicity index. J. Am. Chem. Soc. 1999, 121, 1922-1924. [CrossRef]

17. Parr, R.G.; Pearson, R.G. Absolute hardness: Companion parameter to absolute electronegativity. J. Am. Chem. Soc. 1983, 105, 7512-7516. [CrossRef]

18. Parr, R.G.; Yang, W. Density-Functional Theory of Atoms and Molecules; Oxford University Press: New York, NY, USA, 1989; Volume 16.

19. Kohn, W.; Sham, L.J. Self-consistent equations including exchange and correlation effects. Phys. Rev. 1965, 140, A1133. [CrossRef]

20. Domingo, L.R.; Chamorro, E.; Pérez, P. Understanding the reactivity of captodative ethylenes in polar cycloaddition reactions. A theoretical study. J. Org. Chem. 2008, 73, 4615-4624. [CrossRef] [PubMed]

21. Domingo, L.R.; Pérez, P. The nucleophilicity n index in organic chemistry. Org. Biomol. Chem. 2011, 9, 7168-7175. [CrossRef] [PubMed]

22. Reed, A.E.; Weinhold, F. Natural bond orbital analysis of near-hartree-fock water dimer. J. Chem. Phys. 1983, 78, 4066-4073. [CrossRef]

23. Domingo, L.R.; Aurell, M.J.; Pérez, P.; Contreras, R. Quantitative characterization of the local electrophilicity of organic molecules. Understanding the regioselectivity on diels-alder reactions. J. Phys. Chem. A 2002, 106, 6871-6875. [CrossRef]

24. Domingo, L.R.; Aurell, M.J.; Pérez, P.; Contreras, R. Quantitative characterization of the global electrophilicity power of common diene/dienophile pairs in Diels-Alder reactions. Tetrahedron 2002, 58, 4417-4423. [CrossRef]

25. Domingo, L.R.; Pérez, P. Global and local reactivity indices for electrophilic/nucleophilic free radicals. Org. Biomol. Chem. 2013, 11, 4350-4358. [CrossRef] [PubMed]

26. Jaramillo, P.; Domingo, L.R.; Chamorro, E.; Pérez, P. A further exploration of a nucleophilicity index based on the gas-phase ionization potentials. J. Mol. Struct. THEOCHEM 2008, 865, 68-72. [CrossRef]

27. Pérez, P.; Domingo, L.R.; Aurell, M.J.; Contreras, R. Quantitative characterization of the global electrophilicity pattern of some reagents involved in 1,3-dipolar cycloaddition reactions. Tetrahedron 2003, 59, 3117-3125. [CrossRef]

28. Houk, K.N. Frontier molecular orbital theory of cycloaddition reactions. Acc. Chem. Res. 1975, 8, 361-369. [CrossRef]

Sample Availability: Not available.

(C) 2016 by the authors; licensee MDPI, Basel, Switzerland. This article is an open access article distributed under the terms and conditions of the Creative Commons Attribution (CC-BY) license (http://creativecommons.org/licenses/by/4.0/). 